\title{
Simulation and Design System of Typical Tool for Steam Turbine
}

\author{
XueFeng $\mathrm{Wu}^{1, \mathrm{a}^{*} \text {, GaoCheng Feng }}{ }^{2, \mathrm{~b}}$ and Luo Wen ${ }^{3, \mathrm{c}}$ \\ ${ }^{1}$ Harbin University of Science and Technology, Harbin, Heilongjiang, China \\ awwuxuefeng@hrbust.edu.cn, b18772728807@163.com, 'piaoling.lingchi@163.com
}

\begin{abstract}
Keywords: Steam turbine machining; Deep-hole drilling; UG secondary development; Process optimization; Tool evaluation
\end{abstract}

\begin{abstract}
Machining is the main processing method of the steam turbine system. Due to its complex structure, numerous materials, and complex process, the massive types and quantity of cutting tools generated. The key to improve the machining efficiency and reduce the processing cost is adopting the advanced cutting tools and optimize the process. In this paper, a typical cutting tool design system of multiple functions was established, such as tool management, tool design, tool simulation and process optimization. The working process of cutting tool design and process optimization was described in the case of BTA deep-hole drilling. This system can effectively manage and develop the tools and provide the optimum process parameters, which is of great significance to the high efficiency, high quality and low cost of the steam turbine system.
\end{abstract}

\section{Introduction}

Steam turbine is an essential part of power generation equipment, marine propulsion plant and industry-driven, it will have many applications in various industrial sectors with the development of petrochemical industry, metallurgy, light and textile industry. The main processing method of steam turbine parts is machining, accounts for more than $90 \%$, cutting tools play an important role in solving the steam turbine processing problem. However, machining requires faster processing speed, higher reliability, repeatability and reproducibility, which ask for higher efficiency, precision and security of cutting tools.

Rodriguez, J. A had carried out the sensitivity analysis and showed that neural network modeling could effectively predict and simulate the behavior of life cycles assessment in blades of steam turbines [1]. Bhatt, M. Siddhartha presented improvement in energy efficiency and power loading of steam turbines through module retrofits accomplished by migration from 2-D designs to 3-D designs [2]. Han, IS and Lee, YH et al. developed and applied to the condensing steam turbine network of a chemical plant, reduced the energy cost considerably [3]. Hafid presented the results of research on the manufacturing of steam turbine blade by using investment casting technology [4].

Aimed at the multiple machining tool varieties and the complex processing of steam turbine typical parts, combined cutting tool parametrical design with tool precise design theory and cutting simulation technology, established dedicated tool design and the three dimensional digital simulation integrated platform applied to different type and different series, carried out tool structure parameter optimization and cutting process simulation, in order to reduce tool developing time, improve tool life and ensure the tool reliability. Cutting processing research was carried out to optimize existing manufacturing processes by optimizing cutting parameter, analyzing machining quality, and establishing dedicated database, ensured machining quality and improve efficiency, reduced the cost of machining, promoted the tool application level in the field of energy equipment manufacturing. According to CIRP survey of cutting database economic showed that cutting database processing costs can drop by more than $10 \%$ [5]. This article took the design and simulation of BTA deep-hole drill as an example, presented the design and work process of the system.

\section{Research on Core Technique of Tool Design \& Simulation Platform}

Tool design \& simulation platform is an database platform integrated UG, ANSYS, ABAQUS, the platform have 10 modules, such as the system login, process management, optimization management, 
tool design, tool simulation, machining simulation, system maintenance, experiment management, knowledge base and system help et al., as shown in fig. 1.

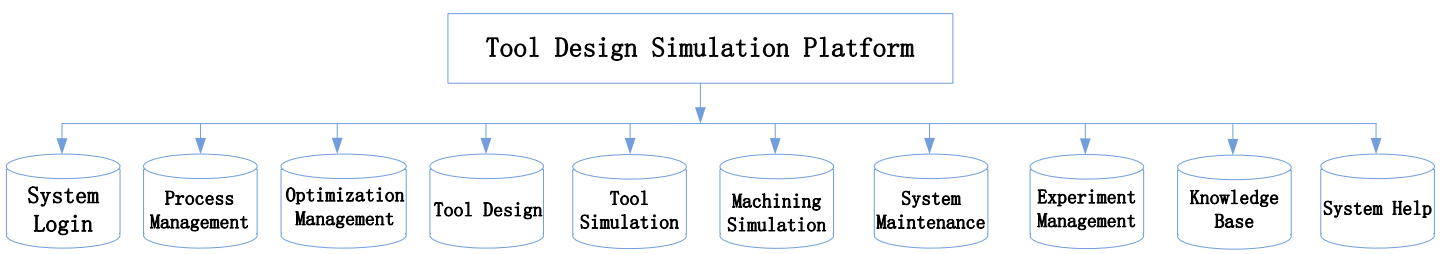

Fig. 1 Tool Design Simulation Platform Block

Tool Design \& Simulation Block Parametric modeling techniques was used to conduct secondary development by UG modeling platform, which can be set selected, tool feature added and modified for different parameters, took rapid preliminary design and modification to the tool, The process of tool design \& simulation is shown in fig. 2. Based on ANSYS, 3D-wave finite element simulation platform, took simulation analysis aim at statics, dynamics and cutting process of tool, then further optimized the tool parameters.

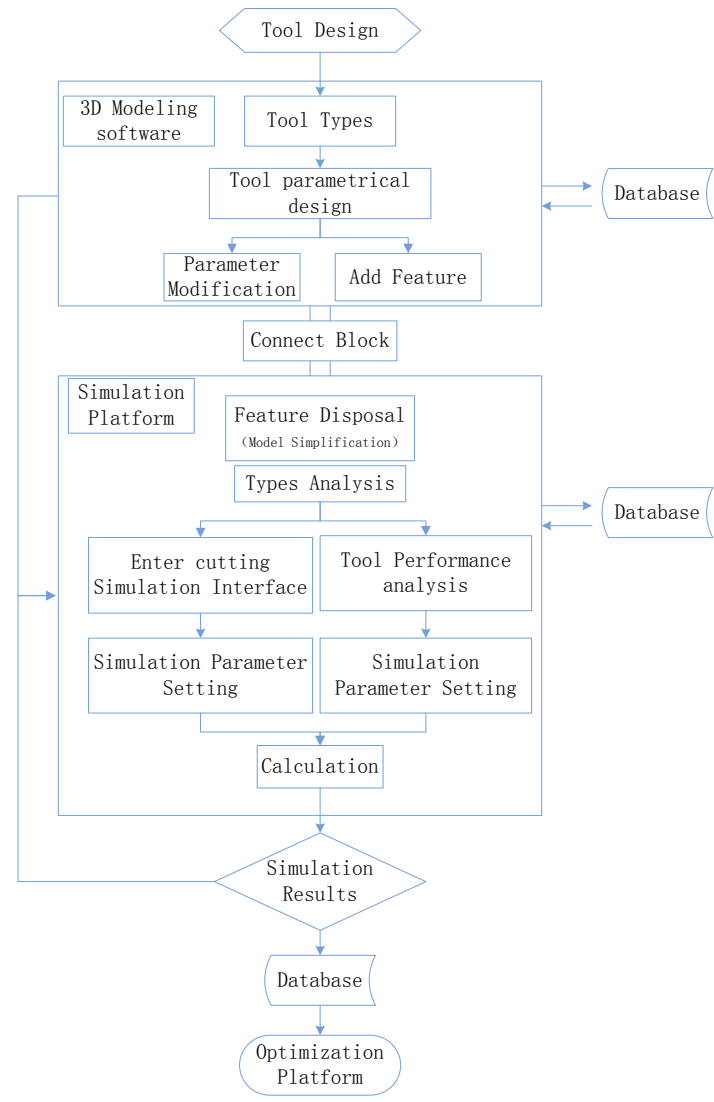

Fig. 2 Process of Tool Design \& Simulation

Model Design. BTA deep-hole drill is a typical structure of deep-hole drill based on single-edged BTA deep-hole drill. Structural characteristics of deep-hole drill: external blade, middle blade, internal blade, guide block, and double BTA hole distribute in cutter body, and cutter body connects with hollow drill bar through the multiple square screw thread. Guide block and cutting edge constitute three-point circle which can guide drilling direction automatically, it provides good orientation and less deflection in the drilling process. Drilling present the structure of three cutting teeth distribution, the main cutting edge is not symmetrical, staggered arrangement, make chip removal smoothly and ensure the stability when drilling into the workpiece.

Method of conducting secondary development by UG was used to do parametric design, cutter body is a normalized stationary model, established standard cutter body model based on different tool 
holder diameter. Took parametric modeling on three blades and two guide blocks, took blade angle and angle parameters as variables, got different tool models, is shown in fig. 3 . Then analyzed the parameters are appropriate or not through simulation, and obtained the appropriate geometric model finally.

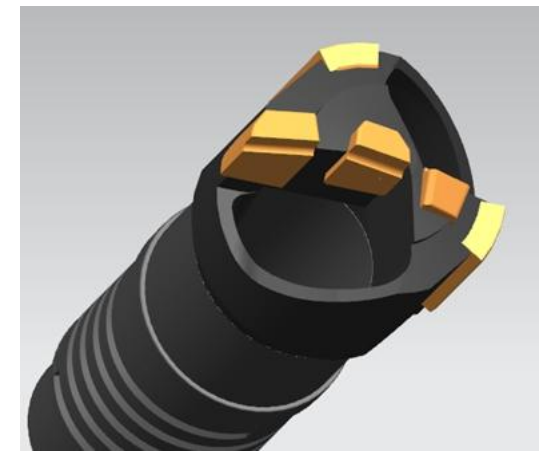

Fig. 3 Geometric Model of Tool

Process Optimization The cutting optimization intends to improve the processing quality and productivity, thereby increasing the profit. Optimization of cutting parameters is to ensure the surface quality of the workpiece and meet the service life of the tool and to meet the user's expectation to achieve the best index actually. The objective function of the optimization of cutting parameters is the lowest production cost, the highest productivity (processing time), and the comprehensive objective function to meet the needs. The optimization process is to determine the design variables, objective functions and constraints, the optimization framework is shown in fig. 4.

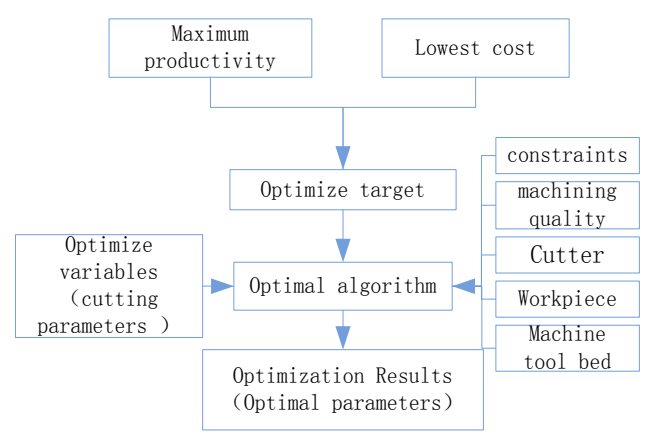

Fig. 4 Optimization Framework

During the processing, the factors affect production efficiency, production cost, surface quality and cutting tool durability are quite a lot, get rid of some unchanged factors such as machine tools bed, cutting tools, workpiece, the cutting speed $\mathrm{v}$, feed $\mathrm{f}$, cutting depth $\mathrm{a}_{\mathrm{p}}$ and cutting width becoming the main factors. According to the actual processing requirements, the objective function of the optimization of cutting parameters is the highest productivity or the lowest production cost.

\section{Design of Simulation and Design System of Typical Tool for Steam Turbine}

Parts of the picture of system working is shown in fig. 5 ,including modules such as system login, process management, optimization management, tool design, tool simulation, machining simulation, system maintenance, experiment management, knowledge base and system help et al.. The system can achieve the main functions of tool design ,tool simulation and tool evaluation. 

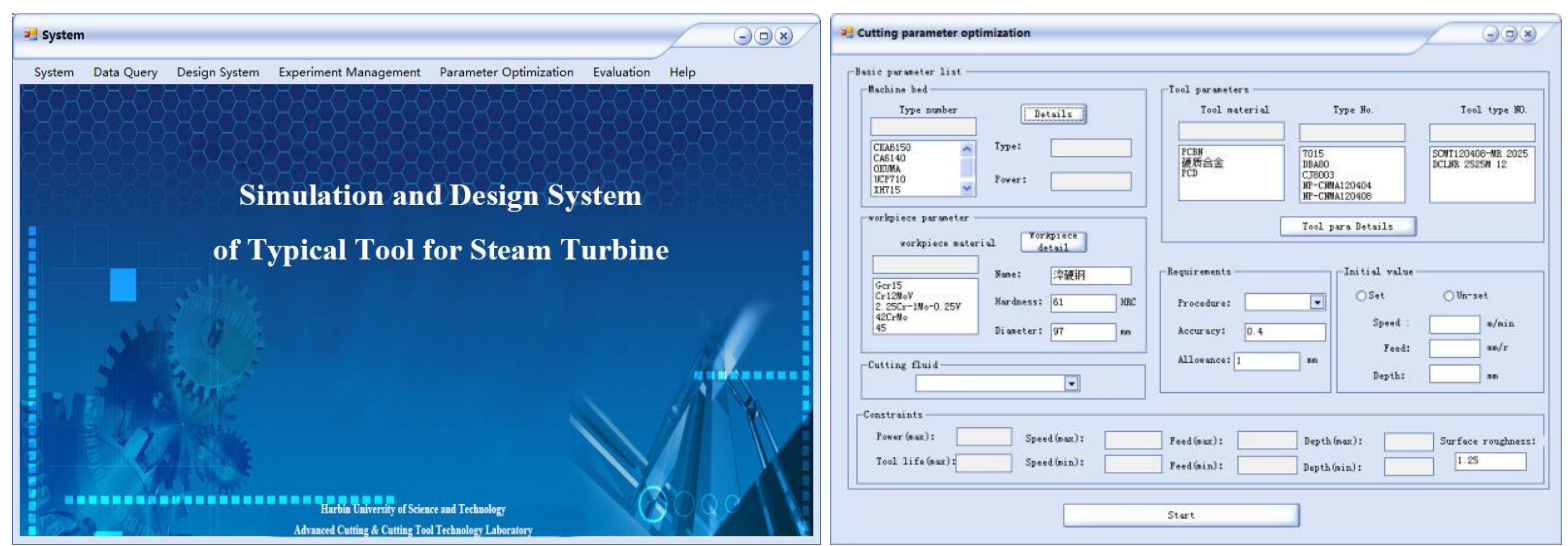

Fig. 5 Parts of the system working

\section{Summary}

In this article, the main function modules of the simulation and design system of the steam turbine are described, and the example of deep-hole drill of the system are introduced.

(1) The tool geometric angles could be conveniently changed through the method of parametric design, and the parameters of the tool were transmitted to the cutting tool simulation module.

(2) Process optimization model was established based on the optimization of the highest productivity and lowest cost. Took the processing parameters in processing parameter base as the process parameters, and the optimum process parameters were obtained by using the process parameters to analyze.

(3) Using the method of BP neural network, established the tool evaluation module, which had the function of self-learning, adaptive and self organization, and the deep-hole drill had been preliminarily evaluated.

\section{Acknowledgement}

Financial support of this work by the National Science and Technology Major Project under Grant No.2013ZX04009-021 is gratefully acknowledged.

\section{References}

[1] Rodriguez. J. A., El Hamzaoui. Y., Hernandez.J. A., The use of artificial neural network (ANN) for modeling the useful life of the failure assessment in blades of steam turbines, submitted to Engineering Failure Analysis, 2013.

[2] Bhatt. M. Siddhartha, Enhancement of energy efficiency and loading of steam turbines through retrofitting 2-d designs with 3-d designs, Journal of Scientific \& Industrial Research, 2011, pp.64-70.

[3] Han. IS, Lee. YH, Han.CH, Modeling and optimization of the condensing steam turbine network of a chemical plant, Industrial \& Engineering Chemistry Research, 2006, pp.670-680.

[4] Hahid, Research On The Manufacturing Of Steam Turbine Blade By Using Investment Casting Technology, Advanced Materials Research, 2013 pp.330-340.

[5] KAHLES J F. Annals of the CIRP, , Vol.36 (1987) No. 2: p. 523-529. 